\title{
The Value of Having a Public Transit Travel Choice
}

\author{
Xuehao Chu \\ Steven E. Polzin \\ University of South Florida
}

\begin{abstract}
The value of having a public transit travel choice is occasionally acknowledged by planners but never quantified; this paper provides a methodology to quantify it. This value of having a public transit choice is in addition to public transit's benefits to users and non-users as a result of the improved performance of other modes in the transportation system resulting from the public transit investment. The value of choice accrues to the total population that has access to public transit, not just those who chose to use it or those who benefit because others have chosen it. This paper develops a methodology and a crude but plausible estimate of the value of choice for public transit using data describing features of U.S. daily personal travel in 1995. For perspective, this estimate is compared with the total operating and capital expense of providing public transit in the United States. The result indicates that the value of choice alone is comparable in magnitude to the cost of providing public transit in this country.
\end{abstract}

\section{Introduction}

\section{Background}

Over the past several years, the transportation planning and policy analysis communities have spent a great deal of time and effort to better understand and 
quantify the various costs and benefits of transportation investments. The increased attention to intermodal and multimodal transportation has included trying to better compare the relative costs and benefits of these modes. The growth in demand for personal transportation has significantly outstripped the increase in supply, and our greater sensitivities to the physical, community, environmental, social, and economic impacts of transportation are motivating continued research into the relationships and magnitudes of various transportation investment impacts. This paper focuses on public transit as an alternative to continued and growing reliance on an urban passenger travel system increasingly dominated by auto travel, most often single passenger auto travel.

One aspect of transportation impacts receiving increased attention is economic impacts. A full understanding of economic impacts is important in investment evaluation and in making policy decisions regarding investment levels for transportation. This paper provides an initial exploration of an aspect of economic impacts of transportation modes typically characterized by the public and policymakers as "the value of having a choice." It is not uncommon to hear one of the arguments favoring the investment in public transit, pedestrian facilities, or bike facilities being the desire to provide a choice of modes to the traveler. Some modal advocates go so far in valuing the virtue of choice as to treat the availability of access by various modes as an issue of equality. Some media and segments of the public have given the availability of multiple modes a high value in rating the attractiveness of urban areas and neighborhoods. Most certainly, the presence of programs and resources to provide a choice of alternative modes is looked at closely when long range transportation plans are adopted in our urbanized areas.

While we may never be able to unequivocally quantify the value of providing a transit, bikeway, or pedestrian option, decisionmakers do have to make real investment decisions that might benefit from being able to estimate the value of choice. A better understanding og methodologies for estimating the value of choice may also have relevance beyond public transit. We may soon be attempting to value the choice of providing the infrastructure to support an additional system of facilities to handle smart or alternatively fueled vehicles. 


\section{A Classification Scheme for Components of the Value of Public Transit}

What is the total value of having public transit available? Figure 1 provides a categorization scheme for the total value of pubic transit. The total value of public transit may be broken down into components: its transportation value, value of choice, and contingency value. Public transit's transportation value and value of choice comprise the consumer surplus of having public transit available. When there is no uncertainty in modal performance, consumer surplus correctly measures the total value of having public transit available. When there is uncertainty, however, consumer surplus may underestimate the total value of having public transit available by the amount of its contingency value.

The traditional approach to measuring economic impacts has focused on the direct and indirect benefits to travelers as a result of the changes in performance of a transportation system in response to the presence of public transit investment. Public transit clearly offers value in instances where it is a productive element in a transportation system. Public transit can provide value as an efficient mover of people. When well utilized it can offer value in saving travel time and reducing land consumption, energy use, air pollution, and infrastructure investments. This value of public transit that results from changes in modal performance may be called its transportation value.

\begin{tabular}{|llll|}
\hline \multirow{2}{*}{$\begin{array}{l}\text { Type of } \\
\text { Value }\end{array}$} & \multicolumn{3}{c|}{ Total Value } \\
\cline { 2 - 4 } & Transportation Value & Value of Choice & Contingency Value \\
\cline { 2 - 4 } Description & $\begin{array}{l}\text { Consumer surplus } \\
\text { from changes in } \\
\text { performance of } \\
\text { modes other than } \\
\text { public transit due } \\
\text { to the presence } \\
\text { of public transit }\end{array}$ & $\begin{array}{l}\text { Consumer surplus } \\
\text { from the presence } \\
\text { of public transit }\end{array}$ & $\begin{array}{l}\text { Value to non-users } \\
\text { because they may } \\
\text { need to use public } \\
\text { transit in the future } \\
\text { because of uncer- } \\
\text { tainty in the availa- } \\
\text { ability of other modes }\end{array}$ \\
\hline Beneficiaries & $\begin{array}{l}\text { Impacted users } \\
\text { and non-users }\end{array}$ & $\begin{array}{l}\text { Accessible } \\
\text { population }\end{array}$ & Non-users \\
\hline
\end{tabular}

Figure 1. Total economic value of pubic transit. 
Going beyond its transportation value, should public transit be valued for its benefit as a travel choice or its value of choice? As tradeoffs in making transportation investments are weighed, how can all the benefits of public transit investments be accounted for? In American culture, the opportunity to have choices in all of the fundamental elements in our lives-from food, shelter, and clothing to medical care, education, and entertainment—are relished. It is logical that we would pursue having choices in our transportation system. This desire to have choices certainly implies that there is value to having mode choices in travel. While public transit's transportation value is included in conventional cost-benefit analysis, transit's value as a travel choice has been largely ignored.

Similarly, we have begun to appreciate what might be called the contingency value of public transit investments. While the virtues of public transit have been well known to northerners who rely on public transit to avoid having to drive in severe ice or snow storms, the 1990s have shown the value of public transit in post-earthquake and post-hurricane situations. While currently a fading memory, the contingency value of public transit can also be appreciated in energy crisis situations. Finally, the contingency value of transit can be appreciated by those who may lose the use of their primary mode due to situations like auto accidents.

\section{Scope of the Paper}

This paper has three objectives. First, it develops a methodology for estimating the choice value of public transit. This methodology is based on Small and Rosen (1981), who developed a simple way of computing consumer surplus when the choices consumers face are discrete. Mode choice for travel is one example of discrete choices. The result developed by Small and Rosen allows one to compute the consumer surplus to travelers of having public transit available. This paper breaks down the consumer surplus into two components. One measures public transit's transportation value, while the other measures its value of choice.

The second objective of the paper is to apply the methodology to daily personal travel in the United States, using the 1995 Nationwide Personal Trans- 
portation Survey (NPTS). The purpose is to develop a crude but plausible estimate of the value of choice. To simplify the estimation, two-point approximations are used for what really are continuous distributions of generalized costs for various modes.

The third objective is to compare the estimated value of choice with the cost of public transit provision. The estimated value of choice, when combined with an estimate of the transportation value of public transit, can be contrasted with the cost of public transit services to help in evaluating transportation investment policies. Unfortunately, the cost of providing public transit cannot easily be disaggregated between that share intended to provide its transportation value and that share intended to provide its choice value. However, it is possible to compare the total cost of providing public transit services with this newly developed value of choice, one of the components of total value outlined in Figure 1. The total cost of providing public transit includes operating, maintenance, and amortized transit capital investments. The result indicates that public transit's value of choice alone is comparable to the total cost of providing public transit. This result may be attributed partly to the fact that the value of choice exists for every person trip for which public transit is available.

\section{Literature}

The concept that choice has value in itself has never been analyzed in the transportation literature, though it has been implicitly acknowledged (e.g., Weyrich and Lind 1996). The economics literature, however, has a large body of work on the concept. Weitzman (1992) provided a general theory of diversity. Both Sattinger (1984) and Perloff and Salop (1985) studied the value of choice in the context of product diversity in general using non-discrete choice models. Anderson and de Palma (1992) studied product diversity in general using the logit model. Suen (1991) studied the value of choice in general using discrete choice models.

Neither economics nor transportation literature provides any empirical estimate of the value of choice. The economics literature, however, does provide insights on three aspects of the issue: 1) how the value of choice may be defined 
in the context of discrete choice models; 2) why the value of choice exists; and 3) what general characteristics the value of choice has.

Definition. Suen (1991) defined the value of choice for an additional product as the change in consumer surplus without changes in the prices of related products or services.

Why Does the Value of Choice Exist? The value of choice arises from the additional chance that a new product or service gives to an individual to find a service that better suits his or her preferences (Sattinger 1984; Suen 1991). Different individuals' valuations for the same product are rarely the same because of differences in their preferences under typical conditions. Even a single individual's valuation of a given product changes with atypical conditions such as weather, natural disasters, one's state of health, and the flow of new information. People's ability to take advantage of these idiosyncratic factors implies that a large set of alternatives is valuable even if there is no taste for diversity as such. In addition, some individuals do have preferences towards diversity itself (Train 1994).

General Characteristics of the Value of Choice. There are several characteristics of the value of choice (Suen 1991):

- People with low valuations for a new product are more likely to have low valuations of existing products; the value of choice from the new product will be limited. For example, adding red buses to already existing blue buses will have little value.

- The larger the variation in random elements or people's preferences, the larger the value of choice.

- The marginal value of choice from additional diversity is positive but diminishing.

- The value of choice is greater from an excellent product and a poor product than from two mediocre products.

\section{Plan of the Paper}

In the balance of this paper, the methodology developed is discussed first, with details in the Appendix. The methodology shows how the value of choice 
may be measured in the context of the logit mode choice model. Then, the methodology is applied to provide a crude but plausible estimate of the annual choice value of public transit in the United States using data from the 1995 NPTS. Finally, the estimate is compared with the cost of providing public transit. Sensitivity of the results is accessed by making changes in several of the assumptions used.

\section{Methodology}

This section describes the methodology developed in this paper for estimating public transit's value of choice. Details of the methodology development are found in the Appendix.

The initial motivation in developing a methodology for estimating public transit's value of choice was to find a measure of the consumer surplus of having public transit available that can be broken down into two components: the transportation value of having public transit available and the choice value of having public transit available.

Small and Rosen (1981) provided just such a measure. Economists long had had simple ways to measure the consumer surplus of someone consuming a certain amount of goods if the goods can be measured with a continuous variable. Small and Rosen (1981) developed a simple way to do the same for consumer choices that are only measured in discrete terms. We face discrete choices in all aspects of our lives, including which airline to fly, which brand of product to buy, and which mode of transportation to use. Small and Rosen's measure allows one to calculate how consumer surplus changes from changes in price, quality, and the number of options available. The Small and Rosen approach to computing consumer surplus is also recommended by the Transit Cooperative Research Program (Cambridge Systematics 1998).

Their measure of consumer surplus has been widely used in measuring the benefit implications of changes in transportation policies. Such policies include deregulation of the airline industry in the late 1970 s and early 1980 s, road pricing, and improvements to roadways and transit systems. More relevant to this paper are applications of their methodology to estimate the consumer surplus of 
having a particular mode. For example, Morrison (1990) used Small and Rosen's method to compute the consumer surplus of having AMTRAK available in specific corridors.

The methodological contribution of this paper is in breaking down Small and Rosen's measure into two components in the context of mode choice. One component measures consumer surplus purely from having a particular mode available, holding the performance of other modes constant. The other component measures consumer surplus as a result of changes in performance of other modes due to having that particular mode available. The second component is the particular mode's transportation value, while the first component is its value of choice.

For this application, the choice for each one-way person trip is among three modes: private modes (automobiles, vans, and trucks), public transit (bus, trolley, and rail), and other modes (bicycling, walking, taxi, school bus, and others). The value of choice per person trip can then be written as the following:

$$
V=-\frac{1}{\beta}\left[\ln \left(1+e^{\beta\left(G_{O}-G_{C}\right)}+e^{\left.\beta\left(G_{T}-G_{C}\right)\right)}-\ln \left(1+e^{\beta\left(G_{O}-G_{C}\right)}\right)\right]\right.
$$

where $\beta$ is the cost coefficient, In is natural logarithm, $e$ is the natural exponential base, and $G_{C}, G_{r}$ and $G_{0}$ are the generalized costs per one-way person trip for private modes, public transit, and other modes, respectively.

A simplifying assumption is made in applying equation (1), which requires information on the differences in generalized costs. In general, the generalized cost for a given mode follows a continuous distribution across different trips-it is probably moderate for some trips but prohibitive for others. Allowing continuous distributions of the generalized costs, however, would require data far beyond the scope of this paper. Instead, a two-point approximation is used for each mode. Specifically, for each of the three types of mode, the generalized cost is the average value for trips for which a particular mode is available, while it is 
infinity for trips for which the particular mode is unavailable. The average values can be determined using the national modal splits among the three types of mode shown in Table 1. The approximations may give different results than using the true distributions. There is no reason, however, to believe that the approximations would alter the magnitude of measurement.

\section{Estimation}

This section examines the magnitude of the value of choice for public transit nationwide and compares this value with the cost of providing public transit in this country, using readily available information. The following areas are covered:

1) assumptions used in the estimation;

2) annual amount of public transit's value of choice nationwide;

3) annual cost for providing public transit in this country; and

4) comparison between the cost and choice value of public transit.

\section{Assumptions}

Table 1 summarizes the assumptions on the modal splits of person trips, annual number of person trips, modal availability, cost coefficient from mode choice models, discount rate, average lifetime of transit capital investments, annual average amount of transit capital investments, and annual transit operating expenses.

The 1995 NPTS is used to derive the modal splits of all person trips among the private modes (including automobiles, vans, and trucks), public transit (including bus, commuter train, streetcar/trolley, and rail), and other modes (including bicycling, walking, school bus, taxi, airplane, Amtrak, moped, and other modes). Public transit accounted for less than 2 percent of all person trips made by people who were 5 years or older in 1995. The total number of person trips from the 1995 NPTS is about 379,000 million.

The distribution of modal availability shown in Table 1 is derived from the 1995 NPTS. Note that the four categories of modal availability are mutually exclusive. The category that transit is available but neither private modes nor other modes are available is not separately listed because it is likely to be a small percentage. 


\section{Table 1}

Assumptions for Numerical Analysis

Modal Split of Person Trips (1995 NPTS)

Private modes (cars, vans, trucks)

Public transit (bus, commuter train, streetcar, and rail)

Other modes (bicycling, walking, school bus, taxi, and others)

Number of Person Trips (1995 NPTS), millions

Modal Availability (1995 NPTS) ${ }^{2}$

No private modes (but with public transit and other modes available)

No other modes (but with public transit and private modes available)

No public transit

All modes available

Cost Coefficient of Mode Choice Model ( $($ )

Discount Rate (r)

Average Lifetime of Transit Capitals $(\mathrm{N})$, years

Annual Amount of Transit Capital Investments (K), millions in 1995 \$

Annual Public Transit Operating Expenses, millions in $1995 \$$

"Information from the 1995 NPTS comes from a research project in progress at the CUTR, "NPTS Travel Data Analysis," funded by the National Urban Transit Institute.

The number of person trips with both public transit and other modes available but no private modes available is about 5 percent. This is based on several factors. The 1995 NPTS shows that about 8 percent of households have no private modes available. Two other factors are likely to make the percentage of person trips with no private modes smaller than that of households with no private modes. One factor is that some of the households without private modes do not have public transit available either. Another factor is that households with no private modes tend to produce fewer person trips than households with private modes. Without specific numbers on these two factors, 3 percentage points are taken off from the 8 percent of households with no private modes.

The number of person trips with both public transit and private modes available but no other modes available is set to one percent. Recall that other modes 
include bicycling, walking, school bus, taxi, and others. It is hard to think of persons who can use public transit or private modes but cannot walk. Without data available on this issue, it is arbitrarily set to 1 percent.

The number of person trips without public transit available is estimated to be about 80 percent. Public transit is defined as available to a person trip if both its origin and destination are within a quarter mile of the nearest transit stop. This definition of spatial transit availability is widely used in practice. The 1995 NPTS shows that about 30 percent of person trips are made by people living within a quarter mile of transit stops.

This number is adjusted down to account for two other factors. First, transit can be considered as available only for trips when it is available for both their origins and destinations. Second, the measure of availability of public transit service is further modified to reflect that fact that transit services are not available at all time of the day and night. Many urban systems have no late night, evening, or weekend service. Even the largest urban areas have very limited geographic coverage of their "nightowl" services. Without specific numbers to account for these two factors, 10 percentage points are subtracted from the 30 percent of person trips made by people who live within a quarter mile. As a result, it is assumed that 80 percent of all person trips do not have public transit available.

The value of the cost coefficient is about the medium value of a range from a review of previous estimates of mode choice models from the literature. Table 2 shows the estimates from eight selected studies. For each study, the table includes estimates of the cost coefficient, year of data, location of data collected, and type of travel. The review shows a range of the cost coefficient from -0.03 to -0.38 . Only eight are selected from a large number of mode choice models estimated in the literature. First, this is not an exhaustive review. Second, some of these studies used specifications that do not estimate the cost coefficient. Third, some other studies do not report enough information so that the value of the cost efficient can be inferred.

The meaning of the cost coefficient may be better understood in three ways. First, the unit of the cost coefficient is the level of satisfaction per dollar of out- 
of-pocket costs of using various modes. In economic terms, it measures the marginal utility of income. Second, the ratio of the in-vehicle travel time coefficient and the cost coefficient in a mode choice model gives the value of in-vehicle time savings. Third, the magnitude of the cost coefficient affects how changes in the out-of-pocket cost of using a given mode affect the odds of that mode being chosen against any other mode. (The odds of one mode against another is the ratio of the probabilities that they will be chosen.) For example, if the cost coef-

Table 2

Selected Mode Choice Studies

\begin{tabular}{|c|c|c|c|c|}
\hline \multirow{2}{*}{ Study } & \multirow{2}{*}{ Estimates } & \multicolumn{3}{|c|}{ Data } \\
\hline & & Year & Location & Type of trips \\
\hline $\begin{array}{l}\text { Stopher } \\
\text { (1969) }\end{array}$ & -0.03 & N/A & $N / A^{2}$ & Urban work \\
\hline $\begin{array}{l}\text { Hensher } \\
\text { (1972) }\end{array}$ & -0.03 & N/A & $N / A^{2}$ & Urban work \\
\hline $\begin{array}{l}\text { Parody et al } \\
\text { (1977) }\end{array}$ & $-0.06 \sim-0.14$ & $1972-1974$ & Boston & Univ.-related \\
\hline $\begin{array}{l}\text { Galbraith/Hensher } \\
\text { (1982) }\end{array}$ & $-0.03 \sim-0.05$ & $1971-1975$ & Australia & Suburban work \\
\hline $\begin{array}{l}\text { Small } \\
\quad(1983)\end{array}$ & $-0.06 \sim-0.14$ & 1972 & San Francisco & Urban work \\
\hline $\begin{array}{l}\text { Dunne } \\
\quad(1984)\end{array}$ & $-0.07 \sim-0.09$ & $N / A^{b}$ & U.K. & Urban work \\
\hline $\begin{array}{l}\text { Morrison/Winston } \\
\text { (1985) }\end{array}$ & $-0.17 \sim-0.38$ & 1977 & U.S. & Intercity \\
\hline $\begin{array}{l}\text { Koppelman/Hirsch } \\
\text { (1989) }\end{array}$ & $-0.17 \sim-0.22$ & 1977 & U.S. & Intercity \\
\hline
\end{tabular}

- The estimates by Stopher (1969) and Hensher (1972) are from a conprehensive review of theory and practice relating to behavioral travel-demand models by Stopher and Meyburg (1976), who do not mention the corresponding years and location of data collection.

${ }^{b}$ Dunne (1984) does not provide information about the year of data collection. 
ficient is -0.1 , then a decrease of one dollar in the out-of-pocket cost of using private modes will increase the odds of private modes being chosen by an individual against any other mode by a factor of $\mathrm{e}^{0.1}=1.11$.

The discount rate is 7 percent, which is required by federal regulations for major transportation investments involving federal funding. The lifetime of transit capital investments varies, depending on the type of investments. Without a distribution of the lifetime of various types of transit investments, an average of 20 years is used. The annual amount of transit capital investments is about $\$ 6$ billion in 1995 dollars. This amount is about the average of the transit capital expenditures for 1992-1995 (APTA 1997: Table 18). These expenditures exclude those made by purchased transportation contractors. Similar data for earlier years are not readily available. The annual amount of transit operating expenses is the nationwide total in 1995 (APTA 1997: Table 27).

\section{The Value of Choice}

Table 3 shows the estimates of public transit's value of choice, based on the methodology described earlier and the assumptions in Table 1. The unit value of choice per person trip varies with modal availability: 0 for trips with no public transit available, about 70 cents for trips with both public transit and other modes available but without private modes, about 10 cents for trips with both public transit and private modes available but without other modes, and about 9 cents for trips with all three types of modes available. Using the distribution of trips by modal availability and the total number of person trips shown in Table 1, these unit values of choice can be aggregated to get a nationwide estimate of about $\$ 18.6$ billion in 1995 . This averages to about 5 cents for every daily person trip in this country.

\section{Cost of Providing Pubic Transit}

The annual total cost of providing public transit includes operating and maintenance expenses and the amortized amount of all transit capital investments that are still within their lifetime. The annual total in the United States in 1995 is about $\$ 26$ billion in 1995 dollars. The annual amount of operating and maintenance expenses is about $\$ 18$ billion, while the annual amount of capital 
Table 3

Resultsa

\begin{tabular}{|c|c|c|c|c|}
\hline \multirow{3}{*}{$\begin{array}{l}\text { Annual } \\
\text { Value of } \\
\text { Choice } \\
\text { (billions } \\
\text { 1995 \$) }\end{array}$} & \multicolumn{4}{|c|}{$\begin{array}{c}\text { Unit Value of Choice by Modal Availablitity } \\
\text { (1995 cents per person trip) }\end{array}$} \\
\hline & \multirow{2}{*}{$\begin{array}{c}\text { No } \\
\text { Public } \\
\text { Transit }\end{array}$} & \multicolumn{3}{|c|}{ Public Transit Available } \\
\hline & & $\begin{array}{l}\text { No Private } \\
\text { Modes }\end{array}$ & $\begin{array}{c}\text { No Other } \\
\text { Modes }\end{array}$ & $\begin{array}{c}\text { All Modes } \\
\text { Available }\end{array}$ \\
\hline 18.6 & 0 & 70 & 10 & 9 \\
\hline
\end{tabular}

'Based on the assumptions in Table 1.

expenses is about $\$ 8$ billion, which is calculated as follows: For a given average lifetime, $\mathrm{N}$, the amortized amount needs to account for all transit capital investments that have been made in the last $N$ years. Given a discount rate, $r$, and an annual average amount of transit capital investments, $\mathrm{K}$, the annual amount of amortized transit capital investments is equal to $\mathrm{N} \mathrm{K} /\left(1-c^{\mathrm{N}}\right)$, where $\mathrm{c}=1 /(1+\mathrm{r})$. The values for $\mathrm{N}, \mathrm{r}$, and $\mathrm{K}$ are shown in Table 1 .

\section{Comparing the Value of Choice and Cost of Public Transit Provision}

The aggregate value of choice and the annual total cost of providing public transit are compared in four ways. First, they are compared, allowing changes in the cost coefficient. Figure 2 shows the results, with changes in the cost coefficient between -0.02 and -0.4 . The annual cost of providing public transit is comparable to the lower estimates but is much lower than the higher estimates of public transit's value of choice. At the median of the range for the cost coefficient suggested by Table $2(-0.2)$, the annual amount of public transit's value of choice in 1995 is about $\$ 18.6$ billion in 1995 dollars, which is slightly more than 70 percent of the annual cost of providing public transit in 1995.

Second, they are compared, allowing changes in the availability of public transit. Figure 2 is drawn with the assumption that public transit is available to 80 percent of all person trips. This estimate of public transit's availability is somewhat uncertain, however. Figure 3 shows the results, with the number of person trips without public transit available ranging between 0 percent and 94 percent. 


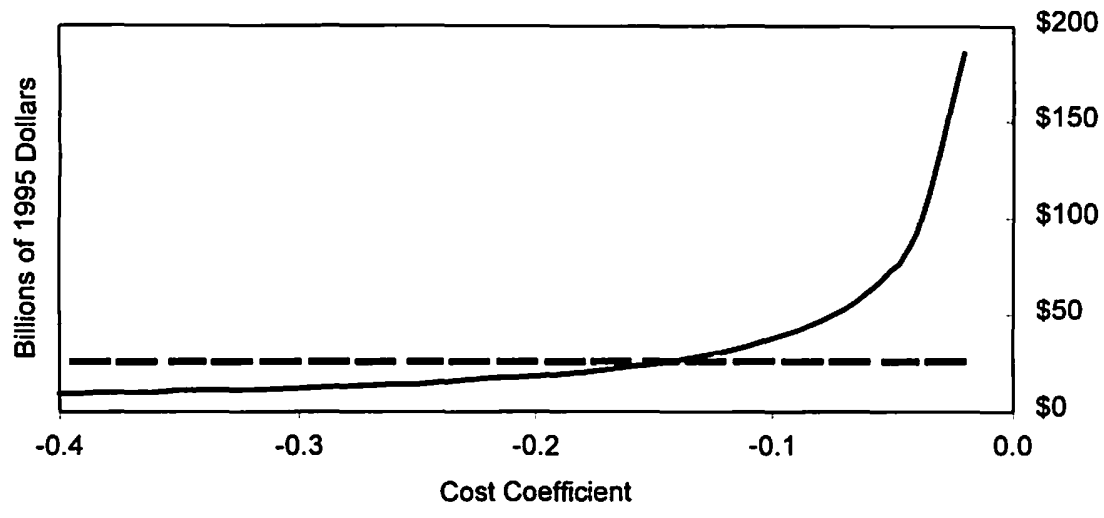

Value of Choice _ _ Cost of Public Transit

Figure 2. Comparison, allowing changes in the cost coefficient, 1995 (based on assumptions in Table 1 except values of the cost coefficient).

The number of person trips with all modes available ranges between 94 percent and 0 percent. The numbers of person trips without private modes available and without other modes available remain at 5 percent and 1 percent, respectively. A value of -0.2 for the cost coefficient is used. For a given value of the cost coefficient, public transit's value of choice decreases linearly with increases in the percentage of person trips without public transit. The value of choice would be about $\$ 46$ billion if public transit were available to all trips and about $\$ 13$ billion if pubic transit were unavailable to any person trips with both private modes and other modes available. The value of choice and cost of providing public transit are comparable in magnitude.

Third, they are compared, allowing hypothetical increases in the modal split of public transit, while the availability of public transit being held constant at 80 percent. Figure 4 shows the results, with the modal split of public transit ranging from 1.8 percent to 50 percent. The calculation for Figure 4 is based on a value of -0.2 for the cost coefficient. The modal split of private modes ranges from 86.3 percent to 38.1 percent, while the modal split of other modes stays constant 


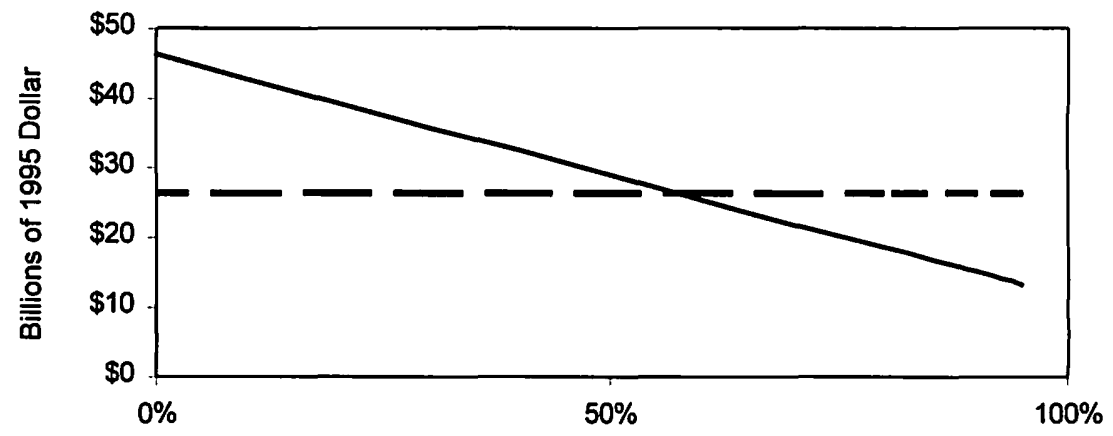

Percent Person Trips without Public Transit Available

Value of Choice - - Cost of Public Transit

Figure 3. Comparison, allowing changes in public transit's availability, 1995 (based on assumptions in Table 1 except percent person trips without public transit available).

at 11.9 percent. The annual cost of providing public transit at each hypothetical modal split of public transit is calculated as follows. First, the cost per trip is computed by dividing the total cost of $\$ 26$ billion by the total number of public transit trips in 1995. Second, this cost per trip is then multiplied by the new number of public transit trips at the increased modal split. Economies or diseconomies of scale in public transit provision are not accounted for in this calculation. The result again indicates that the value of choice and the cost of providing public transit are comparable in magnitude at increased levels of modal split for public transit, especially when transit's modal split is below 20 percent.

Fourth, they are compared, allowing hypothetical increases in the modal split of public transit and changes in the availability of public transit. Figure 5 shows the results. The only difference between Figures 4 and 5 is that public transit's availability is constant in Figure 4 but changes in Figure 5. It is unreasonable to assume that public transit's availability stays constant when its modal split changes. Pubic transit's availability is held constant in Figure 4 because of 
the desire to isolate the effect of increasing public transit's modal split on its value of choice. Public transit's modal split and availability in Figure 5 relate as follows: its availability is 80 percent, 75 percent, 70 percent, 65 percent, 60 percent, 55 percent, and 50 percent when its modal split is 1.8 percent, 5 percent, 10 percent, 20 percent, 30 percent, 40 percent, and 50 percent, respectively. These numbers are somewhat arbitrary because of lack of empirical guidance on how public transit's availability and modal split relate to each other. The result indicates that the value of choice is comparable in magnitude to the cost of providing public transit.

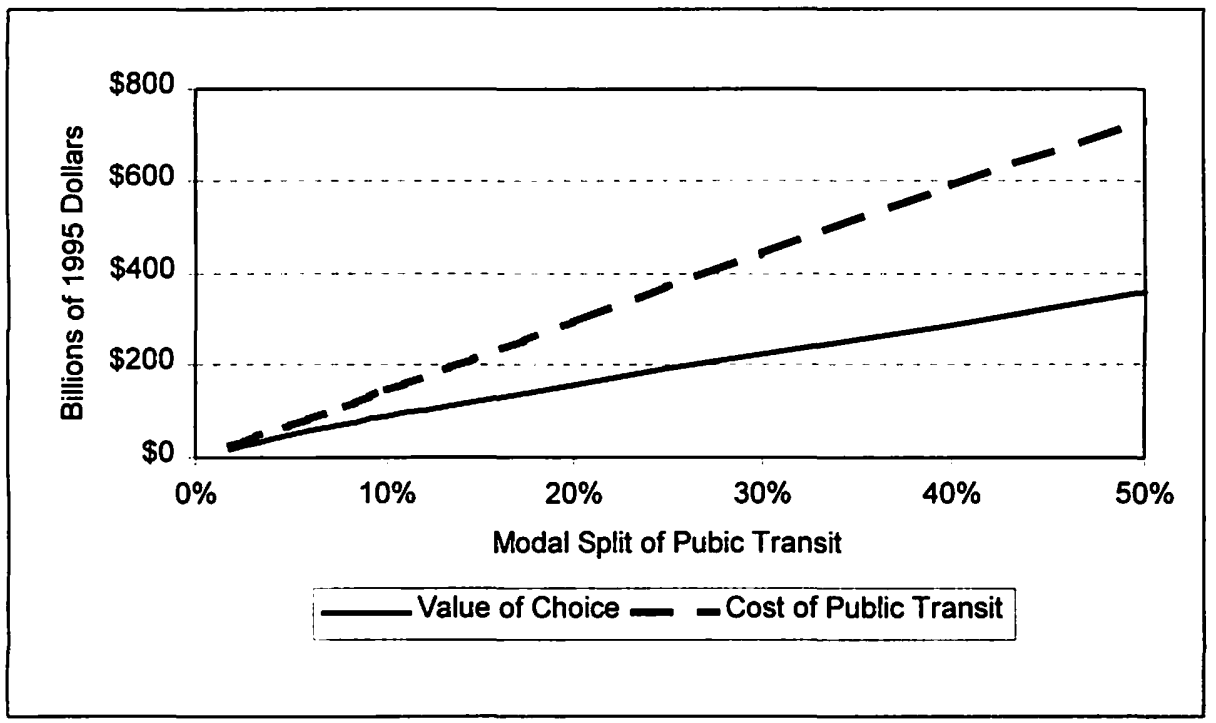

Figure 4. Comparison, allowing increases in public transit's modal split.ab

- The values of choice are based on the following: a value of -0.2 for the cost coefficient; public transit being available to 80 percent of all person trips; modal split of private modes ranging from 86.3 percent to 38.1 percent; and modal split of other modes being constant at 11.9 percent.

- The annual cost of providing public transit at each hypothetical modal split of public transit is calculated as follows. First, the cost of per trip is computed by dividing the total cost of $\$ 26$ billion in 1995 by the total number of public transit trips in 1995. Second, this cost per trip is then multiplied by the new number of public transit trips at the increased modal split. Economies of scale in public transit provision are not accounted for in this calculation. 


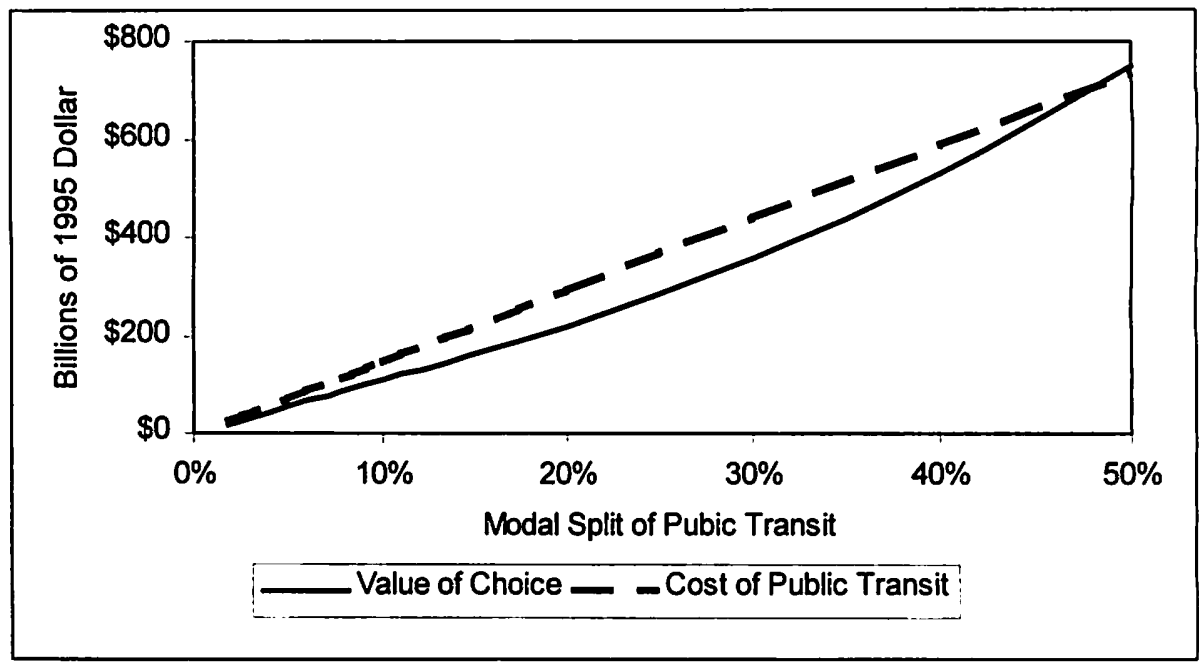

Figure 5. Comparison, allowing changes in transit's modal split and availability.:

- Figure 5 differs from Figure 4 in the following way. In Figure 4, the availabliity of public transit is held constant at 50 percent, while it changes with the modal split of public transit in Figure 5. Specifically, public transit's availability is 80 percent, 75 percent, 70 percent, 65 percent, 60 percent, 55 percent, and 50 percent when its modal split is 1.8 percent, 5 percent, 10 percent, 20 percent, 30 percent, 40 percent, and 51 percent, respectively. These numbers are somewhat arbitrary because of lack of empirical evidence on how public transit's availability and modal split relate to each other.

\section{Conclusion}

The paper has developed a methodology to estimate the value of having a public transit choice. This value is in addition the user and non-user benefits that result from improved performance in the transportation system due to the presence of public transit. A variety of approaches to quantifying the user and nonuser benefits of public transit exist, which result from performance changes. This methodology allows a means of quantifying the value of choice in supplementing the user and non-user benefits for public transit.

This paper has also applied this methodology to provide a plausible though crude estimate of the value of having a public transit choice. Interestingly, the value of choice is comparable in magnitude to the total cost of providing public transit services under a variety of scenarios in this country. In the most reasonable scenario presented, the value of choice nationally was estimated at $\$ 18.6$ 
billion annually. This value alone exceeds 70 percent of the total U.S. cost of pubic transit provision at $\$ 26$ billion annually.

Future research might take two directions. The strategy provides one possible set of estimates for valuing the national presence of transit as a choice. In any given urban area, the planner can use this methodology to develop localized estimates of this value for use in local policy analysis. Second, this paper has estimated the value of choice for public transit through a plausible though crude application of a well-funded methodology. Specifically, the application uses a two-point approximation to what really is a continuous distribution of generalized costs. Future work may explore more refined applications. For example, an application to a metropolitan area may use a mode choice model estimated specifically for this area, which allows one to use the true distribution of generalized costs. Finally, additional exploration of the quantification of contingency value can support efforts to quantify the total value of providing public transit services.

\section{Appendix}

This appendix develops the methodology applied in this paper. The logit mode choice model is first described, followed by the measure of consumer surplus from Small and Rosen (1981). This measure of consumer surplus is then broken down to develop a measure of the value of choice of having a public transit choice.

\section{The Logit Mode Choice Model}

The logit model is widely used in modeling mode choices (Ben-Akiva and Lerman 1985). One behavioral assumption of the model is that an individual chooses among those available to him the mode that would give him the highest level of satisfaction. The level of satisfaction an individual would get from a mode depends a number of things: 1) observed characteristics of the mode, including monetary costs and time spent traveling and waiting; 2 ) observed characteristics of the individual, such as household income and life-cycles; 3 ) unobserved, systematic factors; and 4) unobserved, random factors.

The observed components and unobserved, systematic factors may be summarized as: 


$$
U_{m}=\alpha_{m}+\beta c_{m}+\alpha_{1} i v t_{m}+\alpha_{2} w t_{m}+\alpha_{3} s
$$

where:

$$
\begin{aligned}
& c_{m} \quad=\text { monetary cost of trip making per unit of time via mode } \\
& i v t_{m} \quad=\quad \text { in-vehicle-time of trip making per unit of time via mode } \\
& m \\
& w t_{m} \quad=\quad \text { waiting time of trip making per unit of time via mode } \\
& m \\
& \mathrm{~s} \quad=\text { characteristics of the individual } \\
& \beta, \alpha_{m}, \alpha_{p}, \alpha_{z} \alpha_{3}=\text { coefficients to be estimated. } \alpha_{m} \text { is a mode-specific con- }
\end{aligned}
$$

Each variable in equation (A1) may vary with individuals. A superscript to indicate individuals is not used for simplicity. The unobserved, random factors are captured in an error term not shown in equation (A1). Some of the unobserved factors are random to the analyst but not to the individuals. Examples of such factors include personal characteristics not included in the model, such as crime rates in where an individual lives. Others are random to both the analyst and the individuals, such as weather conditions.

Alternatively, $U_{m}$ may be written as

$$
U_{m}=\beta\left(c_{m}+\frac{\alpha_{m}}{\beta}+\frac{\alpha_{1}}{\beta} i v t_{m}+\frac{\alpha_{2}}{\beta} w t_{m}+\frac{\alpha_{3}}{\beta} s\right)
$$


The terms in the parentheses give the generalized cost of making one trip via mode $m$ :

$$
G_{m} \equiv c_{m}+\frac{\alpha_{0}}{\beta}+\frac{\alpha_{1}}{\beta} i v t_{m}+\frac{\alpha_{2}}{\beta} w t_{m}+\frac{\alpha_{3}}{\beta} s
$$

The probability of an individual choosing mode $m$ is given by:

$$
P_{m}=\frac{e^{\beta G_{m}}}{\sum_{k} e^{\beta G_{k}}}
$$

where $k$ sums over all modes available to the individual and $e$ is the exponential base.

\section{Consumer Surplus Measure}

The denominator in equation (A4) gives the maximum satisfaction an individual can get from the choice situation. Assuming that only one trip is made per unit of time, this maximum satisfaction can be used to measure the consumer surplus to the individual as follows (Small and Rosen 1981):

$$
C S=-\frac{1}{\beta} \ln \sum_{m} e^{\beta G_{m}}
$$

where $-\beta$ is the marginal utility of income, In is the logarithmic function, and $\mathrm{m}$ sums over all modes available to the individual.

The economic benefits of a policy change to the individual per unit of time would be changes in $C S$ because of the policy change. In the case of this paper, the economic benefits of having public transit available is measured by the difference between the amount of consumer surplus with public transit as it is today 
and the amount of consumer surplus without public transit. This measure of benefits applies to users of all modes even if the policy is specific to a particular mode.

\section{The Value of Choice for Public Transit}

For this analysis, it is assumed that the choice for each one-way person trip is among three modes: private modes (automobiles, vans, and trucks), public transit (bus, trolley, and rail), and other modes (bicycling, walking, taxi, school bus, and others). Let $G_{C}, G_{T}, G_{O}$ be the generalized costs per one-way person trip for private modes, public transit, and other modes, respectively. Using equation (A5), consumer surplus per person trip is the following:

$$
C S=-\frac{1}{\beta} \ln \left[e^{\beta G_{O}}+e^{\beta G_{C}}+e^{\beta G_{T}}\right]
$$

The absence of public transit would result in a change in $G_{T}$ from the current value $\mathrm{G}_{\mathrm{T}}$ to an infinitely large value $G^{A}$ (an infinitely large value is equivalent to services not being available), where superscript " $\mathrm{A}$ " indicates the case without public transit available. The absence of public transit may also result in changes in $G_{C}$ and $G_{C}$ from current values $G_{o}$ and $G_{C}$ to $G^{A}{ }_{o}$ and $G^{A}$, respectively. Equation (A6) gives the current amount of consumer surplus per person trip, while the amount of consumer surplus per person trip would be $C S_{\mathrm{A}}=-\ln$ $\left[e^{\beta G_{0}^{A}}+e^{\beta G} \hat{c} / \beta\right.$ without public transit. The difference in consumer surplus per person trip between with and without public transit, i.e., $\triangle C S=C S-C S_{\mathrm{A}}$, gives the total per-trip value of having public transit available.

This value can be broken down into two parts:

$$
\Delta C S=\left[C S-C S^{0}\right]+\left[C S^{0}-C S_{A}\right] \text {, where } C S^{0}=-\ln \left[e^{\beta \mathcal{Q}}+e^{\beta G} \mathrm{c}\right] / \beta
$$

The first component measures changes in consumer surplus without changes in performance of other modes. The second component measures changes in consumer surplus as a result of changes in performance of other modes due to 
having public transit available. The first component is interpreted as the value of choice for public transit, which can be rewritten as:

$V_{\text {all }}=-\frac{1}{\beta}\left[\ln \left(1+e^{\beta\left(G_{o}-G_{C}\right)}+e^{\left.\beta\left(G_{T}-G_{c}\right)\right)}-\ln \left(1+e^{\beta\left(G_{o}-G_{c}\right)}\right)\right]\right.$

Several characteristics of this value are important to point out. First, this value is to individual person trips when the generalized costs are measured for individual person trips. Second, the value applies to all person trips. Third, the formula gives the value of choice for individual trips. For each of the modes, there is a distribution of generalized costs facing different trips. Allowing this variation in generalized costs, however, goes beyond the scope of this paper. Instead, a two-point approximation is used. For each of the three modes, the generalized cost is the average value for trips to which a particular mode is available, while the generalized cost is infinity for trips to which the particular mode is unavailable.

Specifically, if all three modes are available, the value is given by equation (A7). If public transit is unavailable, the value becomes zero: $V_{T}=0$. If private modes are unavailable, the value becomes:

$$
\left.V_{C}=-\frac{1}{\beta} \ln \left[1+e^{\beta\left(G_{r}-G_{O}\right)}\right)\right]
$$

If other modes are unavailable, the value becomes:

$$
V_{O}=-\frac{1}{\beta} \ln \left[1+e^{\beta\left(G_{T}-G_{c}\right)}\right]
$$


Calculating the unit values would require first specifying a value for the cost coefficient from the logit mode choice model, $B$, and then determining the exponential values that appear in equations (A7), (A8), and (A9). In fact, if we let $P_{c} P_{r}$ and $P_{o}$ represent the current modal splits of the private modes, public transit, and other modes, respectively, the above exponential values are equal to the corresponding odds ratios:

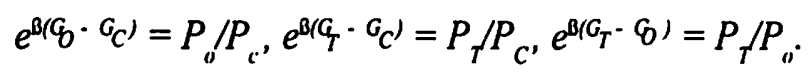

Once the unit values for different levels of modal availability are computed, they can be aggregated over all person trips with the distribution of modal availability. Let $D$ be the annual number of person trips nationwide and $M_{C}, M_{r}, M_{o}$. and $M_{a l l}$ be the shares of person trips that have no private modes available, no public transit available, no other modes available, and all modes available, respectively. Then the annual value of choice may be measured by $V=D\left(M_{c} V_{c}+\right.$ $\left.M_{T} V_{T}+M_{O} V_{O}+M_{u l l} V_{u l l}\right)$, where $V_{C}, V_{r}, V_{O}$ and $V_{u l l}$ are the unit values for the four levels of modal availability.

\section{References}

American Public Transit Association (APTA). 1997. Transit fact book. Washington, D.C.: APTA.

Anderson, S. P., and A. de Palma. 1992. The Llgit as a model of product differentiation. Oxford Economic Papers 44: 51-67.

Ben-Akiva, M., and S. R. Lerman. 1985. Discrete choice analysis: Theory and application to travel demand. Cambridge, Massachusetts: the MIT Press.

Cambridge Systematics, Inc. 1998. Economic impact analysis of transit investments: Guidebook for practitioners. Washington, D.C.: Transit Cooperative Research Program, Report 35, Transportation Research Board.

Dunne, J. P. 1984. Elasticity measures and disaggregate choice models. Journal of Transport Economics and Policy 18(2): 189-203.

Galbraith, R. A., and D. A. Hensher. 1982. Intra-Metropolitan transferability of mode choice models. Journal of Transport Economics and Policy 16(1): 7-29. 
Hensher, D. A. 1972. The consumer's choice function: A study of traveler behavior and values. Unpublished Ph.D. dissertation, School of Economics, University of New South Wales, Australia.

Koppelman, F. S., and M. Hirsch. 1989. Intercity travel behavior: Theory and empirical analysis. In Travel Behavior Research, ed. Brookfield. The International Association for Travel Behavior, USA: Avebury.

Morrison, S. A., and C. Winston. 1985. An econometric analysis of the demand for intercity passenger transportation. In Research in Transportation Economics, Vol. 2, ed. T. E. Keeler. Greenwich, Connecticut: JAI Press: 213-237.

Morrison, S. A. 1990. The value of AMTRAK. Journal of Law and Economics 33: 361-382.

Parody, T. E. 1977. Analysis of predictive qualities of disaggregate modal-choice models. Transportation Research Record 637: 51-57.

Perloff, J. M, and S. C. Salop. 1985. Equilibrium with product differentiation. Review of Economic Studies 52: 107-120.

Sattinger, M. 1984. Value of an additional Firm in monopolistic competition. Review of Economic Studies 51: 321-332.

Small, K. A, and H. S. Rosen. 1981. Applied welfare economics with discrete choice models. Econometrica 49: 105-130.

Small, K. A. 1983. Bus priority and congestion pricing on urban expressways. In Research in Transportation Economics, Vol. 1, ed. T. E. Keeler. Greenwich, Connecticut: JAI Press: 27-74.

Stopher, P. R. 1969. A probability model of travel mode choice for the work journey. Highway Research Record 283.

Stopher, P. R., and A. H. Meyburg. 1976. Behavioral travel-demand models. In Behavioral travel demand models, Proceedings of the Second International Conference on Behavioral Travel Demand, Asheville, N.C., 1975.

Suen, W. 1991. The value of product diversity. Oxford Economic Papers 43(2): $217-$ 223.

Train, K. E. 1994. Self-selecting tariffs under pure preferences among tariffs. Journal of Regulatory Economics 6(3): 247-64.

Weisbrod, B. A. 1964. Collective-consumption services of individual-consumption goods. Quarterly Journal of Economics 78: 471-477. 
Weitzman, M. L. 1992. On diversity. Quarterly Journal of Economics 107: 363-405. Weyrich, P. M., and W. S. Lind. 1996. Conservatives and mass transit: Is it time for a new look? Washington, D.C.: APTA.

\section{Acknowledgment}

We are grateful to F. Ron Jones and three anonymous referees for their comments and suggestions on earlier versions. The research was partially funded by the National Urban Transit Institute (NUTI) at the Center for Urban Transportation Research (CUTR). The content of the paper reflects the views of the authors, not necessarily those of NUTI or CUTR.

\section{About the Authors}

Xuehao Chu, Ph.D., is a Research Associate at the Center for Urban Transportation Research at the University of South Florida in Tampa.

Steve Polzin, Ph.D., P.E., is Deputy Director for Institutes at the Center for Urban Transportation Research at the University of South Florida in Tampa. 